\title{
A Supply Chain Selection Method for Early-Stage Companies Based on an Adapted Quality Function Deployment Optimization Approach
}

\author{
Omar Romero-Hernández \\ Hult International Business School and University of California, \\ Berkeley, USA \\ Email: omar.hernandez@faculty.hult.edu (Corresponding Author) \\ Sergio Romero-Hernández \\ Department of Industrial Engineering and Operations, \\ ITAM, Mexico \\ Email: sromero@itam.mx
}

MV Shivaani

Hult International Business School,

San Francisco, USA

Email: mvshivaani@gmail.com

\begin{abstract}
In this paper, the QFD methodology is adapted to accommodate the assessment and selection of supply chain configurations. This new methodology incorporates a series of factors including supply chain needs, technical specifications, relationships among specifications, and potential synergies. Resultantly, the original contribution of this methodology is the selection of a supply chain scenario that balances the desire to fulfill a series of needs, along with the ability of a supply chain to deliver according to specification. This balance between need fulfilment and availability of supply chain is particularly difficult to strive for early-stage companies. Accordingly, this methodology was applied into the analysis and selection of four different supply chain scenarios considered for the production and final delivery of a large number of customer orders, placed for the Tesla Roadster vehicle, which needed to be fulfilled in record time. In all cases, scenarios were placed in context of the company's mission so that business goals and operating decisions were aligned. The application was successful, and a specific supply chain design scenario was selected. The proposed methodology could be a roadmap for designing incipient supply chains.
\end{abstract}

Keywords: supply chain configuration, quality function deployment, multicriteria analysis, automotive supply chain, functional analysis, early- stage companies

\section{INTRODUCTION}

Startups are increasingly becoming the dominant feature of world economies. They are the harbingers of innovation and job creation. But, in that process they have to continuously adapt their business model to suit to new markets, evolving customer needs and innovative product designs. Operating in such an evolving environment poses serious limits to supply chain selection.
These supply chains are usually immature, unstructured, and scattered across several geographies. In fact, initial supplier selection could be based on time-tomarket concerns (Ayag, 2016) rather than being based on systematic thought out and evaluated processes. As these supply chains grow organically, they face new challenges, including the lack of flexibility to accommodate for constant changes in part specifications and large overhead cost, as not all suppliers are selected based on low-cost network configurations and large lead times in procuring and assembling. One consequence of these disadvantages is the selection of inefficient incipient supply chain, spiraling in later stages of company (Kinski and Bode, 2019). Given the objective of a supply chain to maximize the difference between what the final product is worth to the customer and the effort the supply chain expends in fulfilling customer needs (Karthik, 2006; Kusiak, 2020), its role in startup's success cannot be overstated. However, the traditional supply chain selection methods seem inadequate for these evolving needs and the speed of adjustment required to meet these needs. Accordingly, we propose a novel modified Quality Function Deployment (QFD) based supply chain selection methodology to serve the unfolding needs of startups.

Practitioners extensively use QFD for product development (Gustafsson, 1996; Shen et al., 2000), quality management (Adiano, 1998; Jones, 1988), customer need analysis (Bech et al., 1997), product design (Yang et al., 2000), planning (Ngai and Chow, 1999), engineering (Anderson, 1993; Brady, 2001), decision-making (Startton, 1989), and management (Mclaurin and Bell, 1991). However, despite desirable features of QFD, there is only anecdotal evidence of its use in supply chain selection (Chan and $\mathrm{Wu}, 2002)$. It is noteworthy that for most companies the above-mentioned applications are not mutually exclusive but 
are rather overlapping and there is an increasing industry focus on optimization of processes rather than generic decision-making. Therefore, with the objective of optimization of processes, most recent methodologies have begun to go beyond in their focus from just product to include alignment of product design to business model of the company. In that spirit, optimization models are increasingly using product design and use along with material selection (Tambouratzis et al., 2014), as well as reverse logistics and cost-benefit analysis of post-consumer options such as reuse, recycling, repair, and energy recovery (Huang, 2013).

However, these models are not without limitations. Vijaykumar et al. (2012) caution that

the differences in PSS design processes for different types of PSS (Product/Use/Result oriented) are not discussed. The roles and responsibilities of internal and external stakeholders who may potentially collaborate in the design are not clearly defined. Similarly, Norman et al. (2019 evidence lack of discussion around real-time implementation of these processes. Klibi et al. (2010) carried out a literature review of optimization models for supply chain network (SCN) design problems and reported on the need to develop comprehensive SCN design methodologies. Consequently, Seifbarghy et al. (2010), used Supply Chain Operations Reference Score (SCOR) and TOPSIS to develop benchmarks for integrated supply chain evaluation. Though the metric exhibited improvement in process of case in hand, it had inherent limitations of SCOR such as ignorance of socio-technical aspects in the assessment. In addition, tie- up with company's mission statement, and interaction between specifications and needs was largely missing. This continued need for an integrated model was once again highlighted by Eriksson (2015) and Khan and Wisner (2020) in recent studies where they called researchers to develop a comprehensive conceptual and practical framework. In sum, the question that can we adapt a product design and development (PDD) method to assess and select the best supply chain for an incipient start-up remains unanswered.

To that end, we make an original contribution by proposing a modified QFD approach to be used as an integrated framework by start-ups for their supply chain selection and optimization. We also demonstrate the usefulness of this method by taking the case of its real application for Tesla Roadster. In the process, we make following contributions to the literature on supply chain methodologies: a) we provide an agile (Gyarmathy et al., 2020) multi criteria decision-making tool that is flexible and adept to answer "what-if" analysis; b) we provide a frame of reference, a ready reckoner, to incipient startups for whom the traditional and lengthy supply chain processes are unviable; c) the method facilitates managers to quickly adapt to the changes needed in supply chain by simply altering the evaluation criteria; d) the method helps to provide quicker answer to something that hasn't happened yet as opposed to time-consuming traditional approaches.

The rest of the paper is organized a follows: Section 2 details the methodology of the modified QFD, Section 3 presents real application of modified QFD to Tesla Roadster; last section (Section 4) contains conclusions, limitations and scope of future work.

\section{METHODOLOGY}

Quality function deployment (QFD) is a method within the Design and Development of Products that is focused on the phases of development of concept and design at a systematic level (Ulrich, 2012). QFD was developed in Japan beginning in 1966 to help transform the voice of the customer into engineering characteristics for a product (Akao,1990). This process focuses on understanding what customers want, in terms of the attributes of a product and ensuring that these attributes are effectively translated into the specifications that must be covered with the product (Cross, 2001). Along with the development and use of QFD, there have also been efforts to integrate product design and optimization models. A combined benchmarking and goal programming model that attempts to enhance the effectiveness and efficiency of quality function deployment (QFD) as a means to introduce explicitly the customer's preferences into the design and the production process has recently been proposed along with a numerical example (Cherif, 2014). This model focused on determining a set of engineering characteristics that most effectively meet customer requirements and then, integrates it along designer's preferences and financial factors. Optimization models for QFD planning have also included fuzzy analytic hierarchy process (AHP) to provide weight to customer specifications (Kahraman, 2004). The advantages of adopting QFD and deriving the product architecture solution from a functional approach include a focused design effort and a reduction of time (Romli et al, 2014). However, these models are limited to product design and do not include supply chain evaluations.

QFD has also been adopted as a supplier selection method. Bevilacqua et al. (2006) adjusted the QFD method and tested it in the auto parts industry, specifically in the selection of clutch couplings. The method showed successful application and authors recommended to explore it for larger supplier selection problems that may involve more parts and more players. The present study proposes a methodology to evaluate supply chain scenarios that may potentially serve the needs of new product development projects at start-up companies or at organizations with incipient supply chains. Figure 1 depicts the proposed methodology, which is supported on a modified QFD to evaluate supply chain scenarios.

The operationalization of this novel method starts with the review of the mission statement of the organization. Furthermore, on this first step of the methodology, it is imperative to develop a mission statement for the supply chain. Given that there may be a large number of product specification and supply chain configurations, there is a significant chance that trade-offs and conflicts among specifications may arise. One important criterion to weight on the best design is to keep alignment with the organization's mission. The second step of the methodology includes an identification of needs for the supply chain. These needs may be related to costs, transport modes, times, location, and quality features of the main product. These needs are then expressed as features for the supply chain. These needs are identified through a series of semi-structured interviews to employees of the organization. A round of interviews may give place to several dozens of needs identified. These needs can be reduced in number through an 
aggrupation exercise, where similar needs are grouped by the type of feature that they represent. The third step of the methodology generates a ranking of all groups of supply chain needs. This ranking is expressed as a score that represents the corresponding level of importance.

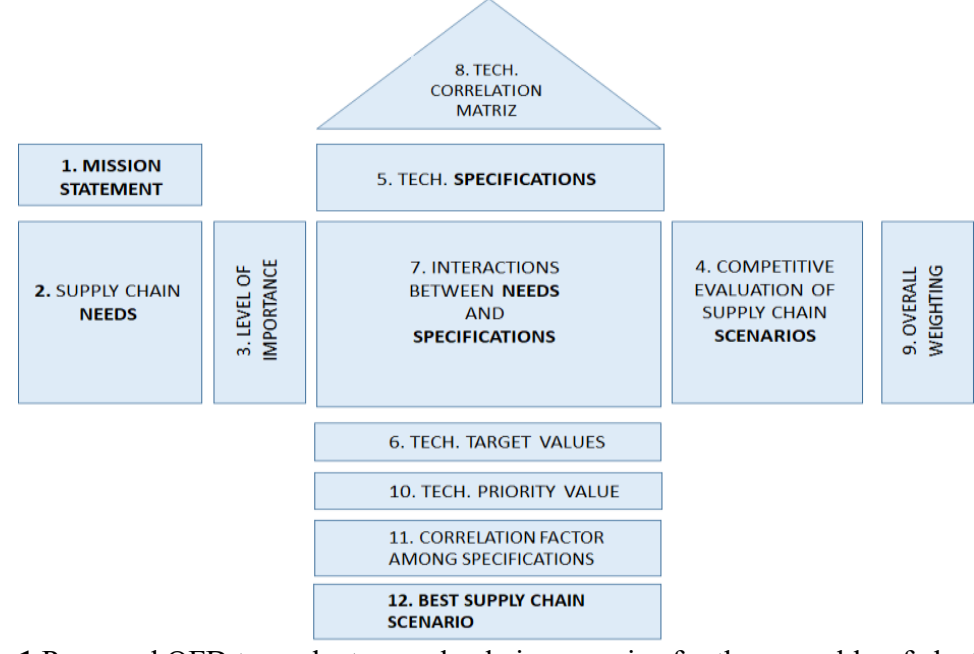

Figure 1 Proposed QFD to evaluate supply chain scenarios for the assembly of electric cars

The fourth step is about the definition of supply chain configurations. Each configuration may represent a potential supply chain scenario that may satisfy, to some extent, the group of needs identified in the second step. The methodology that is proposed in this paper requires at least two supply chain scenarios so that at least one pairwise comparison can be executed. It is unlikely that one supply chain scenario outperforms the other scenarios in all groups of needs. Some scenarios may represent advantages with respect to some needs, while other scenarios may receive a higher score with respect to other needs. Values assigned to each scenario-need pair may be from 1 to 5 . A low value represents a low ability for a scenario to fulfil a need while a high value denotes complete fulfilment, with respect to a target value. On step five, a list of specifications that indicate different courses of action that may be followed to better satisfy the supply chain needs identified in step two is proposed. Each specification must be applied to at least one supply chain need. Specifications must be measurable, must be expressed in specific units, and must include a direction for improvement. On step six, practitioners define a desired target value for each specification $\left(T V_{j}\right)$.

An analysis of the interactions between the supply chain needs (step 2) and the list of specifications (step 5) is carried out on step seven $\left(R_{i, j}\right)$. This is not necessarily a oneto-one relationship analysis. One supply chain need may be fulfilled through one or more specifications. Moreover, the strength by which one specification may fulfil a specific need may not always be as strong as the strength from other specifications. As a result, on this step, supply chain engineers establish at least three different levels to denote the strength of the relationship: weak, medium, and strong. These three levels are also expressed with numerical values such as 1, 3 and 9, respectively. Specifications may also have effects among each other. Two or more specifications may create synergies towards fulfilling supply chain needs while other specification may have a negative effect on other specifications. It is also possible that two or more specifications do not have an effect on each other. Step eight includes an analysis of the relationship among specifications. This relationship can be defined as weak, medium, or strong.
Steps 1 to 8 of the QFD represent a combined baseline among supply chain needs, specification, and supply chain scenarios. The last steps of the methodology are about expressing targets and desired capabilities for a supply chain. The supply chain scenario that fulfills a larger number of needs and gets closer to the desired target goals would be the recommended scenario for the organization to select. The following steps introduce a series of metrics that will be used to quantify the relative performance of each one of the supply chain scenarios. Step nine includes a first metric to quantify supply chain scenarios. This metric includes an overall weighting for each supply chain need with respect to two factors: expected increase on sales and an improvement factor in the level of satisfaction for these needs.

$$
O W_{i}=L I_{i}+\left(1+S P F_{i}\right)(1+I F)
$$

In Equation $1 O W_{i}$ represents the overall weighting for each supply chain need $\mathrm{I} ; L I_{i}$, the level of importance of supply chain needs $\mathrm{i}$ with respect to other needs. In a traditional QFD methodology, $S P F_{i}$, would provide an indication on the effect on sales as a function of different product specifications. In the case of a selection of supply chain scenarios, it is assumed that sales may not be altered. The selection of a supply chain is more a decision on the best way to match supply to a given demand. Under a similar criterion, IF, which is a value ranging from 0 to 1 , represents an improvement factor in product needs expected after each product iteration. This factor may not be applied in a selection of supply chain configurations. The goal of the methodology is to select the best supply chain design and for the purpose of the paper the focus is on selection and not improvement. On step ten, a technical priority value for each $\mathrm{j}$ specification, $T P_{j}$, is calculated. This value provides a reference on the relative priority of each specification to satisfy a specific supply chain need, $i$. There is one technical priority value for each specification and each priority value is calculated as the sum product of all supply chain need and specifications.

$$
T P_{j}=\Sigma_{i} R_{i, j}\left(O W_{i}\right)
$$


From the technical correlation matrix explained in step eight, it was noted that specifications themselves may have a positive, negative, or null relationship with other specifications. This possibility is weighted in step eleven, through a metric that illustrates the existence of correlations between specifications. The inter-specification factor for each j specification, $S P_{j}$, with respect to other specification, $\mathrm{k}$, is presented in equation 3 . The relationship factor for each specification, $R F_{j}$, is a number from 0 to 1 for each specification $\left(R F_{j},=0.1\right.$, in this paper) while $\mathrm{c}(\mathrm{j}, \mathrm{k})$ would denote the existence of a correlation between specification $\mathrm{j}$ and $\mathrm{k}$. A value of zero indicates a non-existent correlation while a value of 1 indicates the existence of a correlation. On step twelve, the assessment and identification of the best supply chain scenario is performed. On this step, two new factors are incorporated. The first factor, $F 1_{j}$, considers the existent trade-offs between specifications and the priority of each specification with respect to each supply chain scenario. This factor brings together all technical specifications and all supply chain needs in equation 4 .

$$
\begin{gathered}
S P_{j}=\left(1+R F_{j}\right)^{\Sigma c_{(j, k)}} \\
F 1_{j}=T P_{j}\left(S P_{j}\right)
\end{gathered}
$$

The second factor, $F 2_{k, j}$ compares the expected performance of each supply chain scenario with respect to the previously established needs and the ability of suppliers to fulfill these needs. $F 2_{k . j}$ uses the scenario values $\left(S V_{i, j}\right)$ of each specification in each supply chain and divides this value by the target value $\left(T V_{j}\right)$ specified in step six. The last two factors are finally combined to calculate a supply chain overall score for each scenario, OSk. This score is the result of the sum product of $F 1_{j}$ and $F 2_{k, j}$. It represents a reference value of each supply chain scenario with respect to what want to be accomplished and what can be accomplished. The best supply chain among all scenario, would receive the highest overall score.

$$
\begin{gathered}
F 2_{k, j}=S V_{i, j} / T V_{j} \\
O S_{k}=\sum_{\forall j}\left(F 1_{j}\right)\left(F 2_{k, j}\right)
\end{gathered}
$$

\section{CASE STUDY: TESLA MOTORS}

The methodology developed and presented in the previous section is applied into supply chain at Tesla Motors. Authors collected information from technical reports and suppliers' contracts to evaluate four supply chain scenarios considered for the production and delivery of the Tesla Roadster, the first large scale automobile produced by the company. The following paragraphs illustrate the main steps discussed in the methodology, from the company's mission, through the identification of needs, specification, and the assessment of supply chain scenarios.

Tesla Motors, Tesla Inc. was incorporated in the USA in 2003. Tesla's primary mission was to commercialize electric vehicles, starting with a premium sports car aimed at early adopters and then moving as rapidly as possible into more mainstream vehicles, including sedans and affordable compacts. The first large scale production model was the Tesla Roadster (Tesla, 2018; Bowman, 2010; Shukla, 2013; Tesla Motors, 2014; Onecle Inc., 2014a, b, c, d; Musk, 2006). A complete view of the evaluation and selection tool is presented in Appendix I. The following sections illustrate the application of the methodology in detail. Partial tables, taken from Appendix I and Appendix V and generated from the tool provide results at various steps of the methodology. These include Tables 1 to 7 and Appendices II to IV. The mission statement for Tesla's Roadster Supply Chain is presented in Table 1. As is evident from Table 1, Tesla Motors, a start-up in the sense that product under consideration is its first large scale roll out, has a priority to produce the product in record time to be able to go for next round of funding with that output. With established suppliers time may not have been a constraint. However, in the case it is 'critical' due to evolving needs and corresponding challenge to adapt that incipient supply chain.

Table 1 (Step 1) Initial supply chain mission for the Tesla Roadster

Product

Business Priorities

Primary market

Secondary market

Assumptions and constraints
The Supply Chain for the Tesla Roadster

Time to market: design and produce the Tesla Roadster in record time and get 2400 units ready before calling for the next round of investment.

Evolve the current perception of corporate responsibility.

Tesla Motors

Supplier of Tesla Motors

This is a recently established company. The supply chain is not yet mature. There is a limited relationship with most suppliers. The supply chain needs to focus on time-to-market above other metrics, such as cost and flexibility.

The major constraint is to meet the delivery date given to customer who have already paid for their cars. The main assumption is that the vehicle will not suffer significant changes from its design. The whole arrangement will use the Lotus Elise for chassis and bodywork. 
Subsequently, following step two of the methodology, a series of semi-structured interviews with supply chain practitioners along with a literature review of Tesla's contracts and official company communications through public statements, SEC reports and blogs serve as the source to establish a first analysis of Tesla's supply chain, main components, participants, and flow of materials. The information collected from the interviews and literature research was synthetized until a first list of 34 needs was completed. These needs are presented in Appendix 1. These 34 needs were subsequently clustered into 9 groups. Each of these 9 groups represent a particular feature of Tesla's supply chain. Per Step 3, another round of interviews was conducted, and practitioners were asked to rank each of the nine groups of needs in order of importance and assign a score from 1 to 5 . A score of 5 represents that the need is 'most important' and score of 1 denotes that the need is 'least important'. The nine groups and their level of importance are presented in Table 2 . It is evident from Table $\mathbf{2}$ that 'flexibility and efficiency of operations' is the most desired feature of supply chain whereas, manufacturing skills and adequate quality control rank much lower.

Table 2 (Step 3) Groups of supply chain needs ranked by their corresponding level of importance

\begin{tabular}{lr}
\hline Supply Chain (SC) Need & L \\
\hline The SC has a flexible, satisfactory, and efficient operation & 5 \\
The SC has a low associated cost & 4 \\
The SC assimilates Tesla's Mission and Philosophy & 4 \\
The SC has a proven record and Reputation in the Industry & 3 \\
The SC has a competent manpower & 3 \\
The SC has a trustworthy manufacturing network & 3 \\
The SC has a reliable manufacturing capacity & 3 \\
The SC has good manufacturing skills & 2 \\
The SC provides an adequate quality control & 2
\end{tabular}

Step four calls for the identification of supply chain scenarios that may be conceived to fulfill the supply chain needs of Tesla Roadster. The scenarios were defined by five main activities that evolved from the original supply chain: (a) fabrication and supply of batteries, (b) reception of batteries and manufacturing of the battery pack, (c) fabrication of the power electronics module, PEM, (d) transport of the PEM and installation on chassis and (e) assembly of all components, PEM, battery pack, powertrain, and chassis. Figure 2 illustrates the corresponding location for each supplier. Figure 2 illustrates how five activities in a single scenario could be scattered across the globe from USA to Thailand. Such geographical dispersion within scenarios along with the time constraint reinforces the need for an integrated supplier chain selection method.

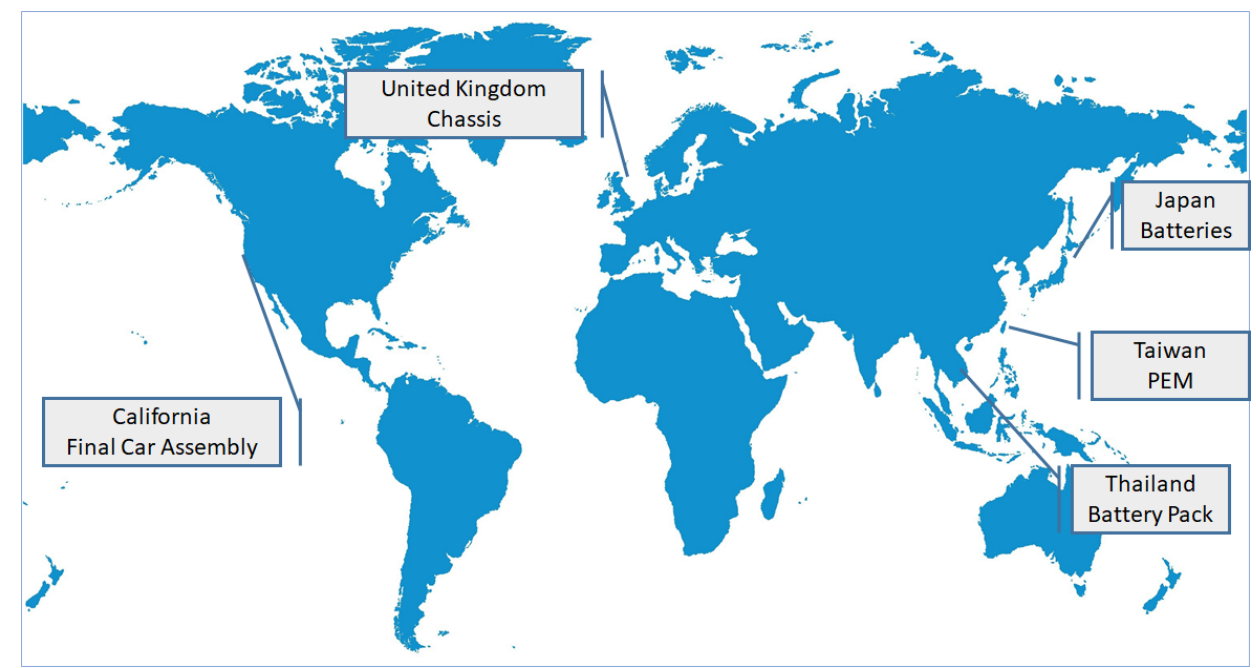

Figure 2 Illustration of a supply chain scenario for the assembly of electric cars

Based on the five activities defined above, four supply chain scenarios under consideration are presented in Table 3. It is pertinent to note that each of the scenarios correspond to a different strategy. Scenario 01 is the one that was already in place but was not performing to the expectations, Scenario
02 is quite extreme-where all activities are internalized by the company and there is no outsourcing, Scenario 03 is based on (offshore) foreign suppliers for selected outsourcing, and Scenario 4 is where the outsourcing is made using only (onshore) American companies. 
Table 3 (Step 4) Supply chain scenarios for the main component-activities of the Tesla Roadster

\section{Scenario 01}

BATTERIES: from Japan (Sanyo) going to Thailand (Xcellent)

BATTERY PACK: from Thailand (Xcellent) going to United Kingdom (Lotus)

PEM: from Taiwan (Chroma ATE) going to United Kingdom (Lotus)

INSTALL PEM AND CHASSIS: in United Kingdom (Lotus)

FINAL ASSEMBLY: at United Kingdom (Lotus) and shipment to California for Final inspection (Tesla)

\section{Scenario 02}

BATTERIES: from Japan (Panasonic) going to California (Tesla)

BATTERY PACK: from California (Tesla) going to United Kingdom (Lotus)

PEM: from Taiwan (Chroma ATE) going to United Kingdom (Lotus)

INSTALL PEM AND CHASSIS: in United Kingdom (Lotus)

FINAL ASSEMBLY: at United Kingdom (lotus) and sent to California for Final inspection (Tesla)

\section{Scenario 03}

BATTERIES: from Japan (Panasonic) going to California (Tesla)

BATTERY PACK: made at California (Tesla)

PEM: from Taiwan (Chroma ATE) going to California (Tesla)

CHASSIS: from United Kingdom (Lotus) going to California (Tesla)

FINAL ASSEMBLY: at California including final inspection (Tesla)

\section{Scenario 04}

BATTERIES: from Japan (Panasonic) going to Texas (Jabil)

BATTERY PACK: from Texas (Jabil) going to California (Tesla)

PEM: from Texas (Jabil) going to California (Tesla)

CHASSIS: from United Kingdom (Lotus) going to California (Tesla)

FINAL ASSEMBLY: at California including final inspection (Tesla)

It is also at this step of the methodology that a first qualitative evaluation of the capacity of each supply chain scenario to fulfil each one of the (9) macro needs is performed. Appendix II presents the score for each combination of supply chain need and supply chain scenario. A score of 1 indicates a weaker ability to fulfil a need while a score of 5 represents a much stronger capability to fulfil the need. For better exposition, consider first row of Appendix II, it indicates that for first macro need - 'The SC has a flexible, satisfactory and efficient operation', Scenario 1, 2, 3 and 4 get a score of 2, 3, 4 and 4 respectively. In operational terms Scenario 3 and 4 demonstrate greater ability to satisfy the stated need as compared to Scenario 1 and 2. This qualitative evaluation prompts the main concerns about each of the supply chain scenarios. There is no single scenario that ranks better than the others with respect to all (9) macroneeds. This evaluation highlights the strengths and weaknesses of each scenario but is not conclusive enough to make a selection. There is a need to create an objective metric method to evaluate the different supply chain needs. These leads to Step 5. At this step, the evaluative method includes a series of technical specifications that may be used to evaluate the ability of each supply chain scenario to fulfil each of the nine-supply chain needs and consequently, the best supply chain scenario. A series of technical specifications is defined in step six. These specifications include a large number of supply chain features that may be represented with specific metrics.

In Step 6, a target value is determined for each specification. These targets valued are based on interviews with practitioners. In order to protect the confidentiality of the data, values have been modified and presented in column heading 'Target value' in Table 4. Accordingly, the given Target Values are simply the average of values assigned to each of the scenarios. To illustrate, the value of 317.5 for first technical specification (transportation costs) is arithmetic mean of values assigned to scenario 1 (600), scenario 2 (300), scenario 3 (200) and scenario 4 (170). In general, these values are based on consensus of various decision makers, however, the usage of average values here does not affect the main goal of this section and the paper, which is to illustrate the application of the methodology and the use of a modified QFD method for the assessment of supply chains. It is noteworthy that the values on the cells are indicative of the level of resource needed in relation to particular scenario. For example, transportation cost of $\$ 170$ corresponding to scenario 4 indicates that it is the most effective alternative in terms of transportation cost. Additionally, an analysis of the interactions between the supply chain needs (step 2) and the list of specifications (step 5) is carried out in step seven. 
Table 4 (Step 5 and 6) Supply chain scenario values for each technical specification

\begin{tabular}{|c|c|c|c|c|c|c|}
\hline \multicolumn{2}{|c|}{ Technical Specification } & \multirow{2}{*}{$\begin{array}{c}\text { Scenario } 01 \\
600\end{array}$} & \multirow{2}{*}{$\begin{array}{c}\text { Scenario } 02 \\
300\end{array}$} & \multirow{2}{*}{$\begin{array}{c}\text { Scenario } 03 \\
200\end{array}$} & \multirow{2}{*}{$\begin{array}{c}\text { Scenario } 04 \\
170\end{array}$} & \multirow{2}{*}{$\begin{array}{l}\begin{array}{l}\text { Target } \\
\text { value }\end{array} \\
317.5\end{array}$} \\
\hline 1 & Transportation costs (\$/car) & & & & & \\
\hline 2 & Variability on transport times (Days) & 4 & 5 & 10 & 7 & 6.5 \\
\hline 3 & Assembly cost (\$/car) & 24 & 13 & 56 & 17 & 27.5 \\
\hline 4 & Components cost (\$/car) & 60 & 70 & 80 & 56 & 66.5 \\
\hline 5 & Carbon footprint (kg CO2e/car) & 23 & 10 & 7 & 15 & 13.75 \\
\hline 6 & Investment ranking index (Moody index) & 1 & 1 & 3 & 2 & 1.75 \\
\hline 7 & $\begin{array}{l}\text { Average level of technical education of } \\
\text { employees (Degree) }\end{array}$ & 1 & 1 & 2 & 1.5 & 1.375 \\
\hline 8 & $\begin{array}{l}\text { Average working experience of workforce } \\
\text { Years }\end{array}$ & 4.5 & 3 & 1 & 2.4 & 2.725 \\
\hline 9 & Number suppliers at Tier 2 and 3 (Number) & 7 & 3 & 12 & 8 & 7.5 \\
\hline 10 & Delays on delivery time (Days/months) & 4 & 2 & 9 & 7 & 5.5 \\
\hline 11 & Overhead capacity to fulfil Tesla's demand (\%) & 17 & 45 & 36 & 28 & 31.5 \\
\hline 12 & Assembly time (hours/car) & 4 & 6 & 12 & 7 & 7.25 \\
\hline 13 & $\begin{array}{l}\text { Specialized production tooling produced } \\
\text { (\#tools/car) }\end{array}$ & 27 & 14 & 18 & 21 & 20 \\
\hline 14 & $\begin{array}{l}\text { Percentage of defective components per batch } \\
(\%)\end{array}$ & 0.3 & 1.1 & 0.08 & 1.2 & 0.67 \\
\hline 15 & Cost for design modifications (\$/car) & 70 & 25 & 18 & 45 & 39.5 \\
\hline
\end{tabular}

It is possible that more than one of the technical specifications identified in step five may satisfy a particular supply chain need identified in step two. As such and as part of step seven, a correlation between technical specifications and supply chain needs is explored. There may be a null, a weak or a strong relationship between specifications and needs. These relationships are expressed with values of 1, 3 and 9, respectively and presented in Appendix III. It is possible that two specifications together may have an amplifying impact on a need or conversely one specification may cannibalize the impact of the other. Accordingly, there is a need to explore the potential additive or subtractive effects between two technical specifications. The pair-wise comparison between technical specifications is presented in Appendix IV. This comparison is performed for all 15 specifications. The upper portion of House of Quality
(Appendix V) indicates whether there is a positive relation or negative relation between two specifications. Subsequently, the Overall Weighting for each supply chain, $O W_{i}$, is analyzed as per step nine of the methodology. In this particular case, there is no expected change in the sales factor, $S P F_{i}$ as a function of supply chain needs. By this stage Orders for Tesla Roadster are already placed and the company is next trying to identify the supply chain scenario that can fulfil more orders in the limited time. Simultaneously, there is no initial change in the Improvement Factor, IFi, given that the focus on this first evaluation is to explore the ability of the supply chains to fulfil all the needs through the technical specifications. As such, the $O W_{i}$ is equivalent to the Level of Importance of each supply need, $L I_{i}$.

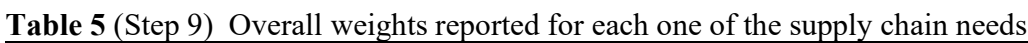

\begin{tabular}{cccccccccc}
\hline & \multicolumn{10}{c}{ Supply chain need } \\
\hline & A & B & C & D & E & F & G & H & I \\
\hline & 5 & 4 & 4 & 3 & 3 & 3 & 3 & 2 & 2 \\
\hline
\end{tabular}

The technical priority value for each $\mathrm{j}$ specification, $T P_{j}$, was calculated as per equation 2 . Likewise, the interspecifications factor, $S P_{j}$ was calculated assuming a reference factor of $10 \%$. This value was considered adequate by practitioners as it assumes the potential existence of synergies but at the same time, it does not distort the overall range of scores. The values of F1 represent the product of multiplying $T P_{j}$ and $S P_{j}$. This value is common across all scenarios. Finally, the corresponding F2 values for each one of the four supply chain scenarios are computed by dividing the scenario value of each technical specification by the target value reported in Table 4. The values of $T P_{j}, S P_{j}, \mathrm{~F} 1 \mathrm{j}$, and F2k,j are presented in Table 6. 
Table 6 Technical priorities, 『TP』 j, inter-specification factors, SPj, Factor 1 and Factor 2 values calculated for a combined system of 9 supply chain needs, 15 technical specifications and 4 supply chain scenarios

Technical Specification

\begin{tabular}{lccccccccccccccc}
\hline & $\mathbf{1}$ & $\mathbf{2}$ & $\mathbf{3}$ & $\mathbf{4}$ & $\mathbf{5}$ & $\mathbf{6}$ & $\mathbf{7}$ & $\mathbf{8}$ & $\mathbf{9}$ & $\mathbf{1 0}$ & $\mathbf{1 1}$ & $\mathbf{1 2}$ & $\mathbf{1 3}$ & $\mathbf{1 4}$ & $\mathbf{1 5}$ \\
$\boldsymbol{T P}_{\boldsymbol{j}}$ & 36 & 27 & 45 & 45 & $\mathbf{1 8}$ & 36 & 45 & 36 & 40 & 45 & 45 & 36 & 27 & 39 & 42 \\
$\boldsymbol{S} \boldsymbol{P}_{\boldsymbol{j}}$ & 1.77 & 1.61 & 1.46 & 1.33 & 1.95 & 1.46 & 1.10 & 1.61 & 1.61 & 1.10 & 1.61 & 1.95 & 1.61 & 1.61 & 1.03 \\
$\mathbf{F 1}$ & 63.8 & 43.5 & 65.9 & 59.9 & 35.1 & 52.7 & 49.5 & 58.0 & 64.4 & 49.5 & 72.5 & 70.2 & 43.5 & 62.8 & 43.3 \\
& & & & & & & & & & & & & & & \\
& & & & & & & & & & & & & & & \\
F2-Scenario 1 & 1.89 & 0.62 & 0.87 & 0.90 & 1.67 & 0.57 & 0.73 & 1.65 & 0.93 & 0.73 & 0.54 & 0.55 & 1.35 & 0.45 & 1.77 \\
F2-Scenario 2 & 0.94 & 0.77 & 0.47 & 1.05 & 0.73 & 0.57 & 0.73 & 1.10 & 0.40 & 0.36 & 1.43 & 0.83 & 0.70 & 1.64 & 0.63 \\
F2-Scenario 3 & 0.63 & 1.54 & 2.04 & 1.20 & 0.51 & 1.71 & 1.71 & 0.37 & 1.60 & 1.64 & 1.14 & 1.66 & 0.90 & 0.12 & 0.46 \\
F2-Scenario 4 & 0.54 & 1.08 & 0.62 & 0.84 & 1.09 & 1.11 & 1.14 & 0.88 & 1.07 & 1.27 & 0.89 & 0.97 & 1.05 & 1.79 & 1.14 \\
\hline
\end{tabular}

The F1 values and the set of F2 values for each one of the four supply chain scenarios represent a reference between what the company wants to accomplish in terms of supply chain and its ability to accomplish it. Accordingly, the overall score is a sum product of F1 values and corresponding F2 values. The score of 816.8 for scenario 1 is based on sum of product of F1 corresponding to each technical specification and F2 for scenario 1 corresponding to the same technical specifications. In the case under consideration, within the realm of multiple supply chain needs and technical specifications, Scenario 3 represents the best supply chain design for the Tesla Roadster. The final score for each supply chain is presented in Table 7.

Table 7 Final score of each supply chain

\begin{tabular}{cc} 
Supply Chain & Overall Score, OSk \\
\hline Scenario 1 & 816.8 \\
Scenario 2 & 709.7 \\
Scenario 3 & 964.1 \\
Scenario 4 & 847.0 \\
\hline
\end{tabular}

Most of the supply chain activities corresponding to Scenario 3 take place in California, which happens to be the place where the Tesla Roadster was finally assembled. Tesla was focused on fulfilling its mission, while at the same time delivering a large number of cars by the corresponding due date of each order. Having a close control on the production line and continuous monitoring of employee performance was paramount. Conversely, Scenario 2 ranked lower among the four supply chain scenarios. Significant increments on distances and lead times as well as less control over production lines turned scenario 2 out into a less attractive supply chain to operate.

\section{DISCUSSION}

The case of Tesla Motors falls under the domain of 'Automobile' industry. Along with shipbuilding it is one of the earliest industry to have applied QFD (Anderson 1993, Stratton 1989, Wang, 1999). However, these applications were limited in scope to Quality Improvement and Design Requirement. In contrast, in the current study, traditional QFD is modified and applied in a novel way towards supplier selection problem. This modified QFD approach resulted in the clear selection of a supply chain alternative on top of the other options. Though the methodology depicted in Figure 1 resembles a traditional QFD approach in shape, the sequence of computations and their nature is vastly different. A traditional QFD has a serial flow of computations going from left to right and top to bottom. In our modified approach the computations are divided into two separate flows, one from the qualitative attributes of the supply chains, (i.e., needs); and another one arising from the qualitative measurements of the supply chains (i.e., technical specifications). These two flows of computations converge at the evaluation of the different options of supply chains in a pincer manner. Consequently, those requirements that have higher relation to needs will have a higher repercussion in final score. Correspondingly it highlights the importance of interdependence of factors. Further the fact that each of the figure in the House of Quality is traceable, enhances the accountability and provides a retraceable trail for quick modification and adaptation. The above highlighted features make the modified QFD an agile and flexible methodology, suitable to ever evolving needs of start-ups.

\section{CONCLUSION, RESEARCH LIMITATIONS, AND FUTURE WORK}

QFD methodologies have been traditionally applied to the design and development of products. In this paper, the QFD methodology is adapted to accommodate for the assessment and selection of supply chain configurations. The 
new methodology incorporates a series of factors including supply chain needs, technical specifications, relationships among specifications, and potential synergies. The final outcome of this methodology is the selection of a supply chain scenario that balances the desire to fulfill a series of needs with the ability of a supply chain to deliver according to specification. This methodology was applied into the analysis and selection of four different supply chain scenarios considered for the production and final delivery of a large number of customer orders, placed for the Tesla Roadster, which needed to be fulfilled in record time. In all cases, scenarios were placed in context to the company's mission so that business goals and operating decisions were aligned. The application was successful, and a specific supply chain design scenario was selected. This scenario, while not the best one for all combinations of needs and specification, resulted to be the best alternative to satisfy most needs (Appendix 2).

The proposed methodology embeds several advantages including the possibility to evaluate and select different supply chain configurations in a relatively short time. This is particularly valuable to start-up companies and organizations who have not yet developed a mature supply chain and are still making decisions along their speedy product development. There are dozens of factors that may be affecting these decisions, including supply chain needs and technical specifications. Combining these factors into a logical framework for decision making was one of the accomplished goals of this methodology. Moreover, the methodology includes a modelling tool, available upon request, that brings more advantages, including the ability to carry out sensitivity analysis among variables and the ability to include more variables and scenarios.

There are limitations in this methodology. Current work needs to be expanded to include a better understanding of the interaction among different rates of supply, and the variability of lead times within supply chain suppliers. Another limitation of the methodology is the absence of a factor to account for supply chain risks including the uncertainty around unpredictable events. A further phase of the present research project considers the definition of potential supply events, along with a likelihood and impact value. These approaches would allow the creation of risks maps which would eventually become part of the decisionmaking process. A last opportunity for further improvement in the methodology is the inclusion on evolving supply chain scenarios. The current methodology is the basis for selecting a supply chain scenario; however, it is expected that a supply chain may continue to evolve and be subjected to additional multi-criteria decisions. Some of these decisions can be supported by the QFD modified approach. Nevertheless, the successful application of modified QFD methodology to real world supply chain problem of Tesla, corroborates the claim for usefulness for incipient supply chains.

\section{ACKNOWLEDGEMENT}

Authors would like to recognize and thank the work and value delivered by research assistant, Rodrigo Nava. Support provided by Asociacion Mexicana de Cultura A.C is appreciated.

\section{REFERENCES}

Akao, Y. (1990). Quality Function Deployment: Integrating Customer Requirements into Product Design ( $1^{\text {st }}$ ed.). New York, USA: Productivity Press.

Adiano, C., 1998. Lawyers use QFD to gain a competitive edge. Quality Progress 31 (5), 88-89.

Anderson, R.E., 1993. HRD_s role in concurrent engineering. Training and Development, 47 (6), 49-54.

Ayağ, Z. (2016). An integrated approach to concept evaluation in a new product development. Journal of Intelligent Manufacturing, 27(5), 991-1005.

Bech, A.C., Hansen, M., Wienberg, L., 1997. Application of house of quality in translation of consumer needs into sensory attributes measurable by descriptive sensory analysis. Food Quality and Preference 8 (5-6), 329348.

Bevilacqua, M., Ciarapica, F.E., Giacchetta, G., (2006). A fuzzy-QFD approach to supplier selection. Journal of Purchasing and Supply Management, 12, 14-27.

Bowman, R. J. (2010). Tesla Motors: A Tale of Beauty and Pain. Supply Chain Brain. Retrieved on March 1, 2019, from https://www.supplychainbrain.com/articles/ 7264-tesla-motors-a-tale-of-beauty-and-pain

Brady, J., 2001. Systems engineering and cost as an independent variable. Systems Engineering, 4 (4), 233241.

Cachon, G. and Terwiesch, C. (2018). Matching Supply with Demand: An Introduction to Operations Management ( $3^{\text {rd }}$ ed.). New York, USA: McGraw-Hill.

Chan, L.K., Kao, H.P., Ng, A., Wu, M.L., 1999. Rating the importance of customer needs in quality function deployment by fuzzy and entropy methods. International Journal of Production Research, 37 (11), 2499-2518.

Cross N. (2001). Engineering Design Methods: Strategies for product Design. West Sussex, England: Wiley.

Cherif, M.S.; Aouni, B.; Chabchoub, H. (2014). A Product Design Methodology and a Global Optimization Models for QFD planning process. International Journal of Applied Nonlinear Science, 1(2), 173-205.

Eriksson, P.E. (2015). Partnering in engineering projects: Four dimensions of supply chain integration. Journal of Purchasing and Supply Management, 21, 38-50.

Gyarmathy, A., Peszynski, K., \& Young, L. (2020). Theoretical Framework for a Local, Agile Supply Chain to Create Innovative Product Closer to End-user: Onshore-Offshore Debate. Operations and Supply Chain Management: An International Journal, 13(2), 108-122.

Gustafsson, A., 1996. Customer Focused Product Development by Conjoint Analysis and QFD. Division of Quality Technology, Department of Mechanical Engineering, Link€oping University, Sweden.

Huang, J. (2013). Optimized Product Design Methodology: A Combinatorial Reverse Logistic Cost-Benefit Analysis Model of WEEPs. Advanced Materials Research, 650, 696-701.

Jones, K., 1988. High performance manufacturing (Part 4): A break with tradition. Industrial Management, 12 (4), 30-32.

Kahraman, C., Erty, T., Buyukozhan, G.(2004). A fuzzy optimization model for QFD planning process using 
analytic network approach. European Journal of Operational Research, 171(2), 390-411.

Karthik, V.N. (2006). An Integrated Supplier Selection Methodology for Designing Robust Supply Chains. EEE International Conference on Management of Innovation and Technology, 2, 906-910.

Khan, H. and Wisner, J.D., (2019). Supply chain integration, learning, and agility: Effects on performance. Operations and Supply Chain Management, 12(1), 14-23.

Klibi, W., Martel, A., Guitouni, A. (2010). The Design of robust value-creating supply chain networks: A critical review. European Journal of Operational Research, 203(2), 283-293.

Kinski A., Bode C. (2019) Startup meets corporate: The multiple facets of the engagement between corporates and startups (Extended Abstract). In: Bode C., Bogaschewsky R., Eßig M., Lasch R., Stölzle W. (eds) Supply Management Research. Advanced Studies in Supply Management. Springer Gabler, Wiesbaden.

Kowalska, M., Pazdzior, M., \& Krzton-Maziopa, A. (2018). Implementation of QFD method in quality analysis of confectionery products. Journal of Intelligent Manufacturing, 29(2), 439-447.

Kusiak, A. (2020). Resilient manufacturing. Journal of Intelligent Manufacturing, 31(2), 269

Liao, K., Deng, X., Wang, Y. G., \& Bayazit, O. Proposing a Framework for Developing Supply Chains of Medical Devices. Retrieved from https://www.researchgate.net/profile/Kun_Liao/public ation/334853633 Proposing_a Framework for_Devel oping_Supply_Chains_of_Medical_Devices/links/5d8 163d4a6fdcc12cb989246/Proposing-a-Frameworkfor-Developing-Supply-Chains-of-MedicalDevices.pdf

McLaurin, D.L., Bell, S., 1993. Making customer service more than just a slogan. Quality Progress, 26 (11), 3539.

Musk, E., (2006). The Secret Tesla Motors Master Plan (just between you and me). Tesla Motors Blog. Retrieved on August 2, 2019, from http://www.teslamotors.com/blog/ secret-tesla-motorsmaster-plan-just-between-you-and-me

Ngai, E.W.T., Chow, D.Y.H., 1999. ICADS: Intelligent car audio design system for product planning. Expert Systems, 16 (1), 19-32.

Norrman, A., \& Naslund, D. (2019). Supply Chain Incentive Alignment: The Gap between Perceived Importance and Actual Practice. Operations and Supply Chain Management: An International Journal, 12(3), 129142.

Onecle Inc. (2014a). Supply Agreement TESLA MOTORS INC. and SANYO Electronics Co. Ltd. Retrieved on November $\quad 12, \quad 2019, \quad$ from http://contracts.onecle.com/tesla-motors/sanyosupply-2007-02-01.shtml

Onecle Inc. (2014b). Supply Agreement LOTUS CARS LIMITED and TESLA MOTORS INC. Retrieved on November 12, 2019, from http://contracts.onecle.com/tesla-motors/lotus-supply2005-07-11.shtml.
Onecle Inc. (2014c). Supply Agreement LOTUS CARS LIMITED and TESLA MOTORS INC. Retrieved on November 12, 2019, from http://contracts.onecle.com/tesla-motors/lotus-supply2009-08-04.shtml

Onecle Inc. (2014d). Supply Agreement TESLA MOTORS INC. PANASONIC INDUSTRIAL COMPANY and PANASONIC CORPORATION. Retrieved on November $\quad 12, \quad 2019$ from http://contracts.onecle.com/tesla-motors/panasonicsupply-2009-07-21.shtml

Romli, F.I.; Rafie, A.; Wiriadidjaja, S. (2014). Conceptual Product Design Methodology through Functional Analysis. Advanced Materials Research, 834-836, 1728-1731.

Seifbarghy, M., Akbari, M. R., \& Sajadieh, M. S. (2010, July). Analyzing the supply chain using SCOR model in a steel producing company. In The 40th International Conference on Computers \& Industrial Engineering (pp. 1-6). IEEE.

Shen, X.X., Tan, K.C., Xie, M., 2000b. Benchmarking in QFD for quality improvement. Benchmarking: An International Journal 7 (4), 282-291.

Shukla, V. (2013). Tesla Motors Deal to Have Little Upside for Chroma: Barclays. ValueWalk. Retrieved on July 31, 2019 from http://www.valuewalk.com/2013/07/tesla-motorsdeal-upside-for-chroma/

Stratton, B., 1989. The refined focus of automotive quality. Quality Progress, 22(10),47-50.

Tambouratzis, T., Karalekas, D., Moustakas, N. (2014). Methodological Study for Optimizing Material Selection in Sustainable Product Design. Journal of Industrial Ecology, 18(4), 508-516.

Tesla Inc. (2018). Tesla. Retrieved on July 31, 2019, from http://www.tesla.com.

Tuan A. Tran and Joon Y. Park (2014). Development of an Integrated Design Methodology for Various Types of Products-Service Systems. Journal of Computational Design and Engineering, 1(1), 37-47.

Tesla Motors (2014). Power Control. Retrieved on November $\quad 12, \quad 2019, \quad$ from http://www.teslamotors.com/roadster/technology/pow er-electronics-module.

Top Gear wiki. 2014. Tesla Roadster. Retrieved on November 12, 2019, from http://topgear.wikia.com/wiki/Tesla_Roadster.

Ulrich K. and Eppinger S. (2012). Product Design and Development. New York, USA: McGraw Hill

Vallet-Bellmunt, T., Rivera-Torres, P., (2013). Integration: attitudes, patterns and practices. Supply Chain Management Int. Journal, 18(3), 308-323.

Vijaykumar, G.; Roy R.; Lelah A.; Brissaud D. (2012). A review of product-service system design methodologies. Journal of Engineering Design, 23(9), 635-659.

Yang, Y.N., Parsaei, H.R., Leep, H.R., Chuengsatiansup, K., 2000. Evaluating robotic safety using quality function deployment. International Journal of Manufacturing Technology and Management 1 (2/3), 241-256. 


\section{APPENDIX 1: LIST OF 9 GROUPS OF NEEDS AND 34 NEEDS IDENTIFIED} FOR THE SUPPLY CHAIN

A) THE SUPPLY CHAIN HAS A FLEXIBLE, SATISFACTORY AND EFFICIENT OPERATION

A1. The Supply Chain has a low transportation cost.

A2. The Supply Chain has a low variability on transport times.

A3. The Supply Chain allows different options of transport.

A4. The Supply Chain follows the best international practices.

A5. The Supply Chain robust under unexpected circumstances

B) THE SUPPLY CHAIN HAS A LOW ASSOCIATED COST

B1. The Supply Chain has a low assembly cost.

B2. The Supply Chain has low components cost.

B3. The Supply Chain has low costs associated with defective parts.

C) THE SC ASSIMILATES TESLA'S MISSION AND PHILOSOPHY

C1. The Supply Chain assimilates Tesla's mission and philosophy

C2. The Supply Chain incorporates or has a sustainability program.

C3. The Supply Chain has a small Carbon Footprint.

D) THE SC HAS A PROVEN RECORD AND REPUTATION IN THE INDUSTRY

D1. The Supply Chain promotes good jobs with adequate wages

D2. The Supply Chain is socially responsible.

D3. The Supply Chain is a good prospect for a long lasting collaboration of mutual benefit.

D4. The Supply Chain has a proven record and good reputation in the industry.

E) THE SC HAS A COMPETENT MANPOWER

E1. The Supply Chain has a good attitude towards learning and training.

E2. The Supply Chain has enough starting basic knowledge.

E3. The Supply Chain counts with a skilled workforce.

E4. There is a good information flow between the Supply Chain and customer.

\section{F) THE SC HAS A TRUSTWORTHY MANUFACTURING NETWORK}

F1. The selection of suppliers does not affect the design of the product.

F2. The Supply Chain does not get highly affected by third party suppliers.

F3. There is a good reliability on second and third level suppliers. 


\section{APPENDIX 1: LIST OF 9 GROUPS OF NEEDS AND 34 NEEDS IDENTIFIED FOR THE SUPPLY CHAIN (CONT.)}
G) THE SC HAS A RELIABLE MANUFACTURING CAPACITY
G1. The Supply Chain has an acceptable sized manufacture facility with extra capacity.
G2. The Supply Chain has an appropriate infrastructure/work line.
G3. The Supply Chain's subcomponent can be used or modified on the customer existing facilities
G4. The SC has capacity enough to meet Tesla's demand to market
H) THE SC HAS GOOD MANUFACTURING SKILLS
H1. The Supply Chain maximizes the use of standardized parts
H2. The Supply Chain delivered components should allow for providing services to other manufacturers
H3. The Supply Chain has the ability to produce specialized production tooling.
H4. The Supply Chain has a low assembly time.
I) THE SC PROVIDES AN ADEQUATE QUALITY CONTROL
I1. The Supply Chain incorporates an adequate quality program.
I2. The Supply Chain has few defective components/parts.
I3. The Supply Chain allows for design and/or quality control capabilities.
I4. The Supply Chain has a low cost for design modifications

\section{APPENDIX 2: (STEP 4) COMPETITIVE EVALUATION OF SUPPLY CHAIN SCENARIOS}

\begin{tabular}{|c|c|c|c|c|c|}
\hline \multirow{2}{*}{\multicolumn{2}{|c|}{$\begin{array}{l}\text { Supply Chain Need } \\
\text { A The SC has a flexible, satisfactory and efficient operation }\end{array}$}} & \multicolumn{4}{|c|}{ Scenario \# } \\
\hline & & 2 & 3 & 4 & 4 \\
\hline B & The SC has a low associated cost & 4 & 1 & 2 & 3 \\
\hline $\mathrm{C}$ & The SC assimilates Tesla's Mission and Philosophy & 2 & 3 & 4 & 3 \\
\hline $\mathrm{D}$ & The SC has a proven record and reputation in the Industry & 2 & 4 & 4 & 4 \\
\hline $\mathrm{E}$ & The SC has competent manpower & 2 & 4 & 4 & 4 \\
\hline $\mathrm{F}$ & The SC has a trustworthy manufacturing network & 3 & 4 & 4 & 4 \\
\hline G & The $\mathrm{SC}$ has a reliable manufacturing capacity & 2 & 3 & 3 & 4 \\
\hline $\mathrm{H}$ & The SC has good manufacturing skills & 2 & 4 & 4 & 3 \\
\hline I & The SC provides an adequate quality control & 1 & 4 & 5 & 3 \\
\hline
\end{tabular}




\section{APPENDIX 3: (STEP 7) RELATIONSHIP MATRIX BETWEEN TECHNICAL SPECIFICATIONS AND SUPPLY CHAIN NEEDS}

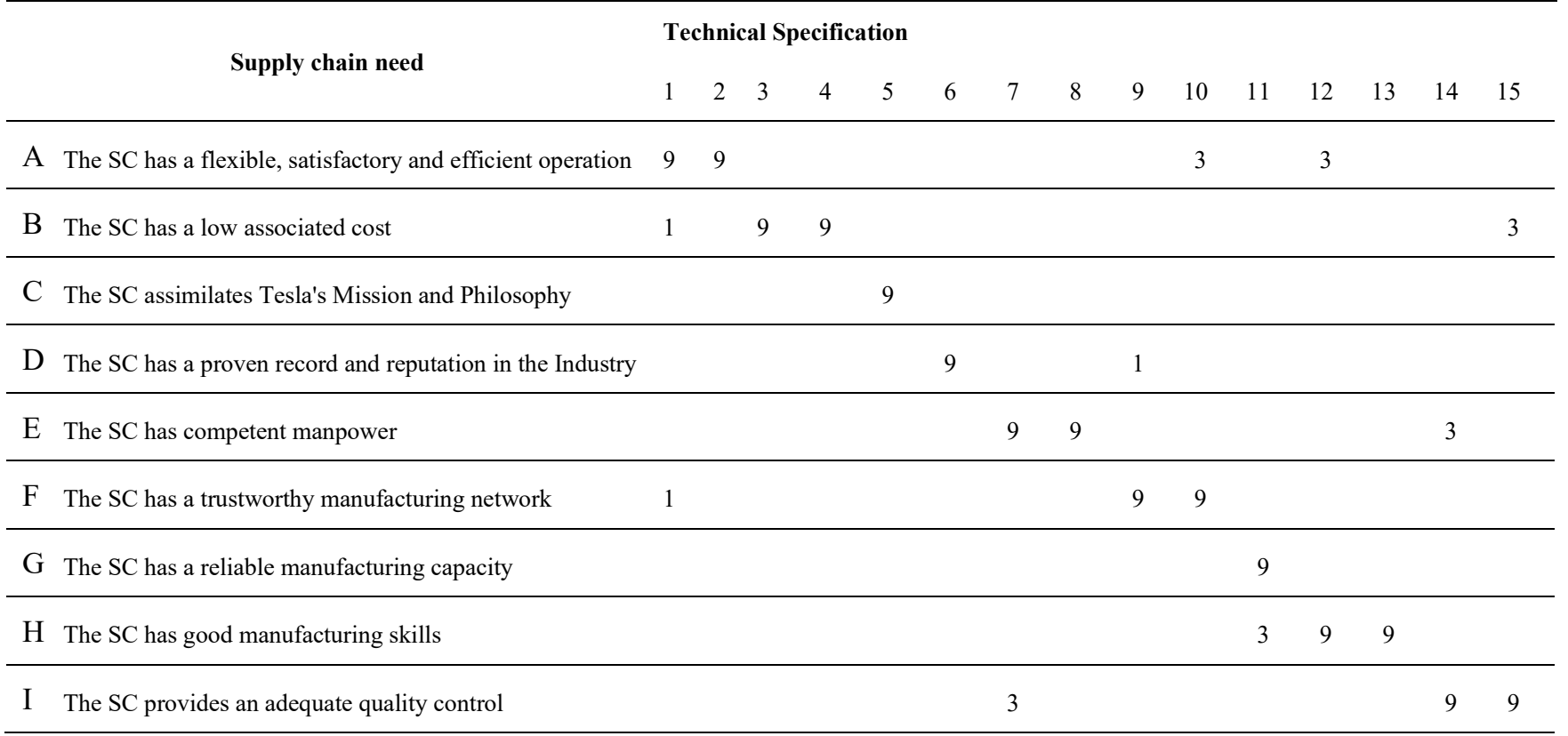

\section{APPENDIX 4: (STEP 8) MATRIX OF CORRELATION AMONG TECHNICAL SPECIFICATIONS.}

\begin{tabular}{|c|c|c|c|c|c|c|c|c|c|c|c|c|c|c|c|c|}
\hline & & \multicolumn{15}{|c|}{ Technical Specification } \\
\hline Technical Specification & & 1 & 2 & 3 & 4 & 5 & 6 & 7 & 8 & 9 & 10 & 11 & 12 & 13 & 14 & 15 \\
\hline Transportation costs & 1 & & & & & & & & & & & & & & & \\
\hline Variability on transport times & 2 & - & & & & & & & & & & & & & & \\
\hline Assembly cost & 3 & & - & & & & & & & & & & & & & \\
\hline Components cost & 4 & & & & & & & & & & & & & & & \\
\hline Carbon footprint & 5 & & - & - & - & & & & & & & & & & & \\
\hline Investment ranking index & 6 & & - & & & & & & & & & & & & & \\
\hline $\begin{array}{l}\text { Average level of technical education of } \\
\text { employees }\end{array}$ & 7 & & & - & & & & & & & & & & & & \\
\hline $\begin{array}{l}\text { Average working experience of } \\
\text { workforce }\end{array}$ & 8 & - & & - & & - & - & & & & & & & & & \\
\hline Number of suppliers at Tier 2 and 3 & 9 & - & & & & - & + & & & & & & & & & \\
\hline Delays on delivery time & 10 & & & & & & & & & & & & & & & \\
\hline $\begin{array}{l}\text { Overhead capacity to fulfill Tesla's } \\
\text { demand }\end{array}$ & 11 & & & & - & - & & & & & - & & & & & \\
\hline Assembly time & 12 & - & - & & & & + & & - & & & - & & & & \\
\hline Specialized production tooling produced & 13 & + & & & & & & & & - & & - & - & & & \\
\hline $\begin{array}{l}\text { Percentage of defective components per } \\
\text { batch }\end{array}$ & 14 & - & & & - & & & & & - & & & & - & & \\
\hline Cost for design modifications & 15 & & & & & & & & & & & & - & & - & \\
\hline
\end{tabular}




\section{APPENDIX 5: HOUSE OF QUALITY}
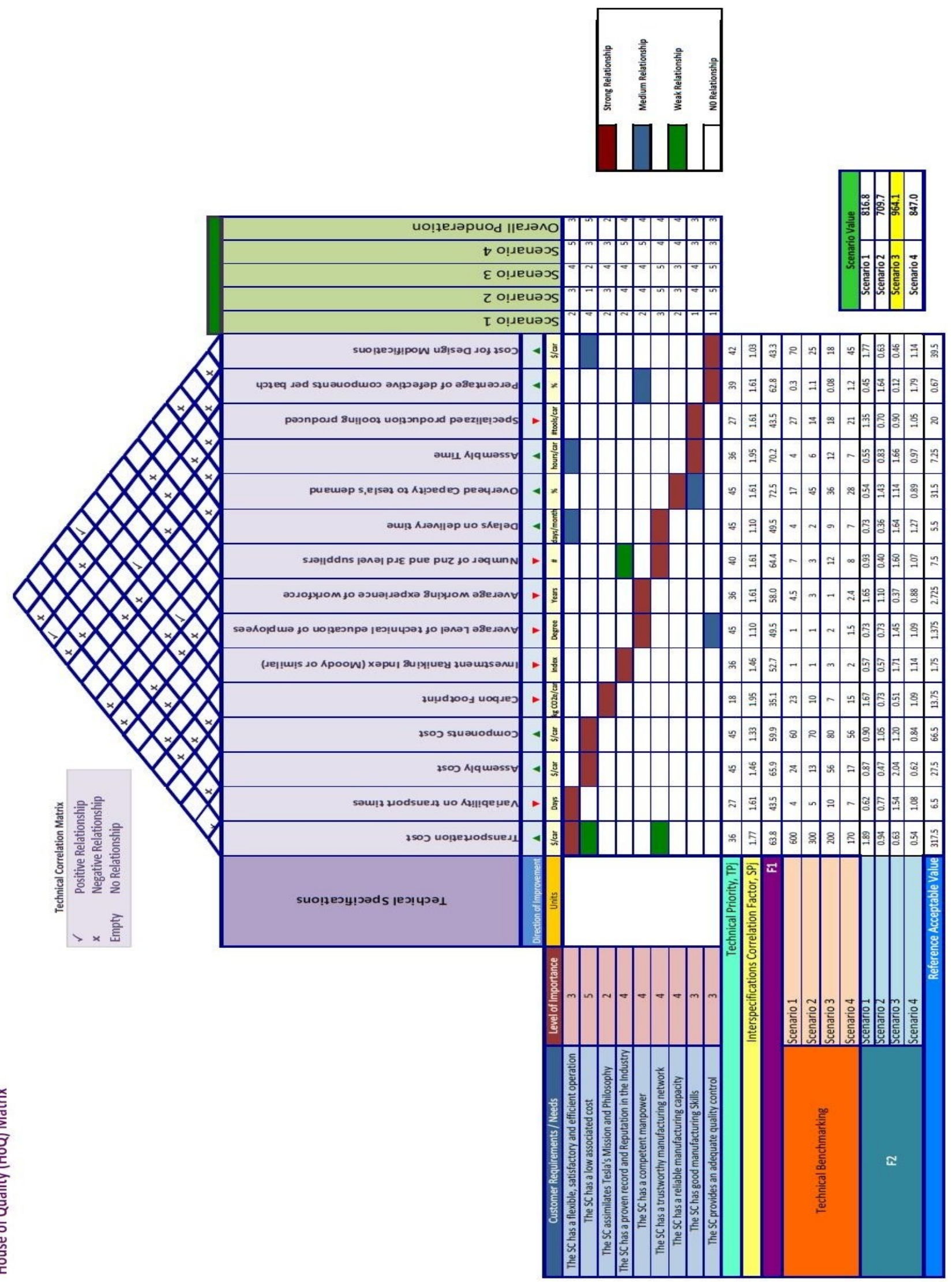
Prof. Romero-Hernandez was a recipient of the 2010 Franz Edelman Award, the world's most prestigious award on Operations Research and Management Science. Chemical Engineer with graduate studies in Economic Policy and Government and a $\mathrm{PhD}$ in Process Economics and Environmental Impact from Imperial College, England. He has worked for a diverse range of public and private organizations such as Procter \& Gamble, PEMEX (Oil \& Gas), Accenture, and the Ministry for the Environment and Natural Resources. Professor and researcher at Hult International Business School and a faculty member at the Haas School of Business of the University of California, Berkeley. He has received dozens of teaching and research awards in the USA and internationally. Currently, he is a National Researcher, and author of various books including: Introduction to Engineering, Renewable Energy Technologies and Policies, and Industry and the Environment and several international publications on project management, business modelling, green operations and sustainable development. He has led several internationally awarded projects in the field of supply chain, sustainable business strategies, renewable energy and business processes - sponsors include the United Nations, Ministry of the Environment, Industry consortiums, S\&P 500 companies, the Stock Exchange and NGOs.

Sergio Romero-Hernandez is the Director of the Center for Technological Development (CDT) at ITAM, where he works as a full-time research-professor. He is founder and coordinator of the Diploma on Planning and Direction of Operations at the Direction of University Extension and Executive Development at ITAM. He is a Mechanical Engineer of UNAM; Master of Science and Doctor of Engineering at the Imperial College of Science, Technology and Medicine, London, England. Specialty in "Competing through productivity and quality" by the Productivity Standards Board Corporation sponsored by the Ministry of Foreign Affairs, Singapore. In the public sector he was anointed as a member of the Advisory Council for Sustainable Use of Energy, SENER, by the Minister of Energy. During his appointment, the first National Program for the Sustainable Use of Energy, PRONASE, was established, as well as several normativities on energy efficiency. In the private sector, he worked in England for The Turbo Genset Company, as well as ICON Consultants. He has participated in consultancy projects in design and analysis for the Rolls-Royce Centre for Vibration Engineering and British Petroleum in the UK. In Mexico he has done consulting projects for the INE, SEMARNAT, Securities Depository Institute (Indeval), BAL Group, Mexican Petroleum Institute, SENER, INTEC, and various SMEs. He has published articles in refereed journals and books worldwide. Likewise, he is the co-author-editor of the textbook "Introduction to Engineering" in their two editions, this book has a widespread distribution in all Ibero-America. He is also the main author in renewable energy in Mexico books, published by the Woodrow Wilson International Center for Scholars. He has been recognized by the Government of Singapore, Beihang University in Beijing, China, the University of California, Berkeley and CONACYT in Mexico among others. He spent his sabbatical leave in the University of California, Berkeley, where he did research on the environmental impact of the production of photovoltaic solar panels. He has been appointed National Researcher by the National Research System.

MV Shivani is a PhD in Management from Indian Institute of Technology Delhi (IITD). She was selected as a part of $35^{\text {th }}$ Indian Scientific Expedition to Antarctica by Ministry of Earth Sciences, Govt. of India, for her research project on Optimization of inventory at Indian Research Station. She is a qualified Chartered Accountant and graduate from Asia's top Business College. She has been a faculty at prestigious Indian Institute of Management (IIM) and is currently associated with Hult International Business School, USA. She has presented her work in 7 countries across 4 continents and is widely published in journals of international repute. She has a Springer monograph to her credit on 'Corporate Risk Management'. 